\title{
Assessment on Storage Conditions of Medical Laboratory Commodities and KAP of Store Managers at Government Hospitals in Addis Ababa, Ethiopia
}

\author{
HABTAMU MOLLA TESFAW ${ }^{1}$ AND KELEMEWORK HUSSIEN ${ }^{2}$ \\ ${ }^{1}$ Department of Medical Laboratory Sciences, College of Health Science, Addis Ababa \\ University, Addis Ababa, Ethiopia \\ ${ }^{2}$ Minillik II hospital, Addis Ababa, Ethiopia \\ Email: habtamumolla8@gmail.com
}

Received: August 16, 2017l Revised: August 29, 2017| Accepted: September 06, 2017

Published online: October 02, 2017

The Author(s) 2017. This article is published with open access at www.chitkara.edu.in/ Publications

\section{Abstract}

Background Medical laboratory commodity management system especially storage system of laboratory supplies is a challenge for health professionals. Lacks of proper storage condition for laboratory commodities causes damaging commodities and stock out of essential supplies. The need of proper store management has gained a great attention for better laboratory service.

Methods A Cross sectional study was conducted to assess storage conditions of commodities in eleven hospital medical stores in Addis Ababa from 1 January 2014 to 1 February 2014. A structured questionnaire was used to collect the data. Data was entered to EPI INFO version 3.1statistical software and analyzed with SPSS version 20 statistical analysis software. Graphs and tables were used to present the result.

Results Data obtained from eleven governmental hospitals was analyzed. From these more than $45 \%$ of hospitals stores served for more than 12 years without amendments. Around $18 \%$ of hospital stores didn't have adequate protection from sunlight whereas more than $90 \%$ didn't have frozen storage of either $-20^{\circ} \mathrm{C}$ or $-70^{\circ} \mathrm{C}$. But all of the stores had cold storage of $2-8^{\circ} \mathrm{C}$. Only $36.36 \%$ of the hospital stores have separate flammable chemicals and $54.45 \%$ of hospital stores have separate hazardous chemicals. All store managers in this study are pharmacist and most of them are degree holders.

Journal of Multidisciplinary Research in Healthcare Vol-4, No-1, October 2017 pp. 11-21 
Tesfaw, HM Hussien, K

Conclusion The storage conditions of majority of the hospitals have problems. Lack of adequate space and infrastructures to store medical laboratory commodities were challenges in half of the facilities. Adequate and regular training should be given to the responsible personnel for better storage of medical laboratory commodities.

\section{INTRODUCTION}

Commodity management can be defined as the process of getting commodities, controlling, transporting, storing and distributing them. [1]

Storage of commodities ensures the physical integrity and safety of supplies, and their packaging, throughout the various storage facilities, until they are dispensed to clients. [2]

Commodities storage conditions and protecting supplies quality until their expiration date is important for serving customers and conserving resources. [3]

Managing commodities in any setting (public or private sector) and at any level (local, regional or national) require appropriate knowledge of store keepers. [4]

Guidelines for the storage of commodities are a practical reference for those managing or involved in setting up a store room or warehouse. The guide contains written directions and clear illustrations on receiving and arranging commodities, special storage conditions, tracking commodities, maintaining the quality of the commodities, constructing and designing a medical store. [5]

Flammables and corrosives commodities should be stored separately from other commodities and reagents. They require several levels of temperature storage, including cool storage. Commodities that deteriorate rapidly when exposed to light or moisture specimens (fragment of tissue) require freezing. [6]

The timeliness and accuracy of diagnostic results is reliant on the availability of laboratory commodities that meet minimum quality standards. [7]

Laboratory capacity depends on the availability of the required commodities to perform tests, with most tests requiring multiple commodities to be available simultaneously. Well-functioning supply chains will enhance availability of the commodities required to provide the necessary laboratory services. [8]

Health service delivery in Ethiopia is characterized by poor quality health service resulting due to lack of well trained store manager, a very limited physical health infrastructure, inadequate space, and shortage of commodities at health facilities. [9]

Assessing the storage condition of commodities in hospital stores and knowledge, attitude and practices of store managers will provide important information and input for policy makers and health facilities to improve their store management of health commodities. 


\section{METHODOLOGY}

\subsection{Study setting and area}

The study was conducted in eleven government hospitals medical stores among these five are federal and six regional hospitals medical stores located in Addis Ababa, the capital city of Ethiopia, seat of African Union and Economic Commission.

\subsection{Study design and period}

Cross sectional study was conducted from 1 January 2014 to 1 February 2014
Assessment on Storage Conditions of Medical Laboratory Commodities and KAP of Store Managers at Government Hospitals in Addis Ababa, Ethiopia

\subsection{Population}

\subsubsection{Source population}

All health facility stores and their store managers controlling and managing health commodities in Addis Ababa

\subsubsection{Study populations}

All government hospital stores found in Addis Ababa and their store managers

\subsection{Sampling technique and sample size}

Purposive sampling technique was used to select the study populations. All eleven governmental hospitals main stores which had medical laboratory commodities, found in Addis Ababa were included. Eleven persons who are store managers of each hospital working during the data collection period.

\subsection{Data collection procedure}

A structured questionnaire was used. Two data collectors were trained and provided the guide how to collect data on the storage of medical laboratory commodities and KAP of the store managers.

\subsection{Study variables}

\subsubsection{Dependent variables}

Commodities storage condition and KAP of store managers

\subsubsection{Independent variables}

Socio-demographics characters, training of store managers, availability of guide line, educational back ground, temperature condition, storage problems and standard storage space 
Tesfaw, HM

Hussien, K

\subsection{Data quality management}

Questionnaire was pre tested to ensure the validity of the tool. After the data collection tool was pretested, appropriate modification was made, vagueness was avoided and it became easily understandable. Data collectors were trained and provided the guide line for how to collect data. Principal investigator made frequent checks on the data collection process to ensure the completeness and consistency of the gathered information. Data was double entered to enable cross-checking during analysis as well.

\subsection{Data analysis}

The data was cleaned, coded and entered by using EPI INFO version 3.1 Statistical software. Then data was exported to SPSS version 20 statistical soft ware for analysis. Results were presented in tables and figures. Fisher's exact test was used to show the association between dependent and independent variables. $P$ value less than 0.05 was considered as significant.

\section{RESULTS}

\subsection{Store distance, numbers and service year}

All hospitals had at least one medical store. Two hospitals have four medical stores each. Five (45.45\%) of hospital store were served for more than 12 years.

Table 1: hospital store distance, area of stores and service year of governmental hospital stores in Addis Ababa, from 1 January 2014 to 1 February 2014.

\begin{tabular}{ll}
\hline $\begin{array}{l}\text { Store distance from main laboratory } \\
\text { (in meters) }\end{array}$ & $\begin{array}{l}\text { Number of hospital stores } \\
\text { No. }(\%)\end{array}$ \\
\hline $100-200$ & $10(90.9)$ \\
$300-500$ & $1(9.1)$ \\
Area of store rooms $\left(\right.$ in $\left.{ }^{2}\right)$ & \\
$30-50$ & $1(9.1)$ \\
$60-80$ & $2(18.18)$ \\
$90-100$ & $1(9.1)$ \\
NE & $7(63.64)$ \\
Service of store rooms ( in years) & \\
$1-4$ & $1(9.1)$ \\
$5-8$ & $2(18.18)$ \\
$>12$ & $5(45.45)$ \\
NE & $3(27.27)$ \\
\hline NE: not explained &
\end{tabular}




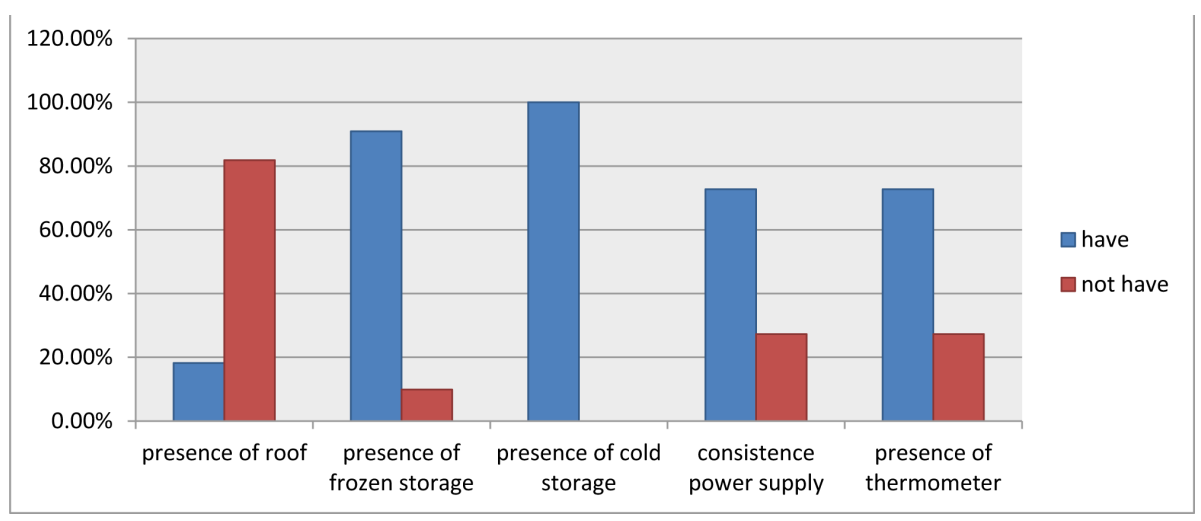

Assessment on Storage Conditions of Medical Laboratory Commodities and KAP of Store Managers at Government Hospitals in Addis Ababa, Ethiopia

Figure 1: A chart shows presence of necessary conditions in eleven hospital stores at Addis Ababa.

The service year of three stores was not explained. The area of medical stores was not explained in seven of the hospitals. Except one of the medical stores, majority (90.9\%) of the medical stores were 100-200 meters far from the main laboratory.

\subsection{Presence of necessary materials in hospital stores}

Two $(18.18 \%)$ of the hospital stores do not have a roof to avoid sunlight and water penetration. Ten $(90.9 \%)$ of the hospital stores did not have frozen storage of $-20^{\circ} \mathrm{C}$ or $-70^{\circ} \mathrm{C}$. All of the medical stores had cold storage $2-8^{\circ} \mathrm{C}$. Three $(27.27 \%)$ stores had not consistent power supply and generators. Three $(27.27 \%)$ of stores did not have thermometer in the rooms.

\subsection{Presence of written guidelines and training opportunities}

Six $(54.55 \%)$ of store managers said that they didn't take any training about storage of medical supplies. Only five (45.45\%) hospital stores had written guideline for storing medical laboratory supplies or commodities according to their specification. Except one hospital medical store, 10 (90.9\%) of them followed manufacturer's instruction or WHO guide line for appropriate storage of commodities. Six (54.55\%) of the medical stores had a standard guide line to discard and incinerate dangerous chemicals and give training to the responsible person.

\subsection{Storage habit of hospital stores}

Only four $(36.36 \%)$ of the hospital stores did separation of flammable chemicals whereas six $(54.55 \%)$ of them did separation of hazardous 
Tesfaw, HM Hussien, K

chemicals. Majority (90.9\%) of hospital stores did separation of damaged/ expired supplies from normal commodities. Four (36.36\%) of the medical stores did separation of flammable, hazardous, damaged/expired medical laboratory commodities. Seven $(63.64 \%)$ of the medical stores had sufficient space to store all available medical laboratory commodities in the stores. Eight (72.74\%) of the hospital stores had adequate number of shelving and boxes.

\subsection{Knowledge of store managers}

All of the store managers in the eleven governmental hospitals in Addis Ababa were pharmacists. Ten (90.9\%) of store managers are degree holders; only one store manager is diploma holder. Six (54.55\%) of them were females.

All sore managers respond that they knew the appropriate storage of cool chain items. Nine $(81.81 \%)$ of the store managers responded that they knew appropriate storage of frozen items. Four $(36.36 \%)$ store managers knew what quality commodity means. Three $(27.27 \%)$ of store managers maintained the quality of medical laboratory commodities using standard guidelines and the rest maintained the quality of medical laboratory commodities using manufacturer's manuals.

Majority (90.9\%)) of the store managers knew the need of separate storage for flammable chemicals. Ten of the store managers knew that medical laboratory commodities should be protected from direct sun light and all medical laboratory commodities should be stored at temperatures according to their specifications.

\subsection{Attitude of the store managers}

All of the store managers thought that standard guidelines were important for appropriate storage management of medical laboratory commodities. Seven $(63.64 \%)$ of the store managers thought that monitoring store temperature was necessary and six (54.55\%) thought that the quality of their store was in compliance with the standard storage guideline.

\subsection{Practice of the store managers}

Two (18.18\%) of the stores managers store rapidly deteriorating items by preventing them from direct sun light and moisture whereas the rest store managers used guidelines for storing rapidly deteriorating items. Four $(36.36 \%)$ of the store managers didn't take any actions when the temperature is out of range while others did adjustments. Eight (72.73\%) store managers regularly cleaned refrigerators. 
Table 2: Attitude of store managers in eleven governmental hospital stores Addis Ababa, from 1 January 2014 to 1 February 2014.

\begin{tabular}{ll}
\hline Attitude related questions & $\begin{array}{l}\text { Number of store managers } \\
\text { No. }(\%)\end{array}$ \\
\hline $\begin{array}{l}\text { Importance of standard guide line } \\
\text { Yes }\end{array}$ & $11(100)$ \\
No & 0 \\
Necessity of monitoring store room & \\
temperature & $7(63.64)$ \\
Yes & $4(36.36)$ \\
No & \\
Storage condition of your commodities & \\
$\quad$ Compliance with standard guide line & $6(54.55)$ \\
$\quad$ Did not compliance with the & $5(45.45)$ \\
standard guide line & \\
&
\end{tabular}

Assessment on Storage Conditions of Medical Laboratory Commodities and KAP of Store Managers at Government Hospitals in Addis Ababa, Ethiopia

Training status of store managers has a significant association with the general medical laboratory storage condition.

Table 3: Practice of store managers in eleven governmental hospital stores in Addis Ababa, from 1 January 2014 to 1 February 2014.

\begin{tabular}{ll}
\hline Practice related questions & $\begin{array}{l}\text { Number of store managers } \\
\text { No. }(\%)\end{array}$ \\
\hline $\begin{array}{l}\text { Storage of rapidly deteriorating items } \\
\text { According to guidelines }\end{array}$ & $9(81.82)$ \\
By preventing windows from sun light and & \\
moisture & \\
Measure taken when temperature is out of & $7(63.64)$ \\
range & $4(36.36)$ \\
$\quad$ Adjusting & \\
$\quad$ Do nothing & \\
Cleaning and deforesting refrigerators & $8(72.73)$ \\
$\quad$ Yes & $3(27.27)$ \\
$\quad$ No & \\
Way of cleaning and deforesting refrigerators & $7(87.5)$ \\
$\quad$ Using other refrigerator & $1(12.5)$ \\
$\quad$ I don't know & \\
\hline
\end{tabular}


Tesfaw, HM Hussien, K

Table 4: Association of selected variables with the general storage condition of medical laboratory commodities in eleven governmental hospitals in Addis Ababa, from 1 January 2014 to 1 February 2014.

\begin{tabular}{|c|c|c|c|c|c|}
\hline & & \multicolumn{3}{|c|}{$\begin{array}{l}\text { General storage condition of } \\
\text { laboratory commodities }\end{array}$} & \multirow[b]{2}{*}{$P$ value } \\
\hline & & $\begin{array}{l}\text { Good } \\
\text { N }(\%)\end{array}$ & $\begin{array}{l}\text { Not good } \\
\text { N }(\%)\end{array}$ & $\begin{array}{l}\text { Fisher's } \\
\text { exact test }\end{array}$ & \\
\hline $\begin{array}{l}\text { Education status of } \\
\text { store managers }\end{array}$ & $\begin{array}{l}\text { Diploma } \\
\text { BSc }\end{array}$ & $\begin{array}{l}1(100) \\
3(30)\end{array}$ & $\begin{array}{l}0(0) \\
7(70)\end{array}$ & 2.2 & 0.14 \\
\hline $\begin{array}{l}\text { Presence of written } \\
\text { guidelines }\end{array}$ & $\begin{array}{l}\text { Yes } \\
\text { No }\end{array}$ & $\begin{array}{l}4(57) \\
2(50)\end{array}$ & $\begin{array}{l}3(43) \\
2(50)\end{array}$ & 4.86 & 0.08 \\
\hline $\begin{array}{l}\text { Presence of } \\
\text { adequate space }\end{array}$ & $\begin{array}{l}\text { Yes } \\
\text { No }\end{array}$ & $\begin{array}{l}2(33) \\
2(40)\end{array}$ & $\begin{array}{l}4(67) \\
3(60)\end{array}$ & 0.05 & 0.82 \\
\hline $\begin{array}{l}\text { Training of store } \\
\text { managers }\end{array}$ & $\begin{array}{l}\text { Yes } \\
\text { No }\end{array}$ & $\begin{array}{l}4(100) \\
0(0)\end{array}$ & $\begin{array}{l}0(0) \\
7(100)\end{array}$ & 3.2 & 0.003 \\
\hline
\end{tabular}

\section{DISCUSSION}

All eleven hospitals have at least one medical store. From these $45.45 \%$ hospital stores served for more than twelve years without any amendments and $90.9 \%$ of hospital stores far from main laboratory in the range of 100 meters to 200 meters. These findings are in line with the study conducted in Tanzania. [17]

In this study around $18.18 \%$ of hospital stores didn't have roof for protection of commodities from sunlight as well as from water penetration and majority of stores around $90.9 \%$ didn't have frozen storage at temperature of $-20^{\circ} \mathrm{C} /-70^{\circ} \mathrm{C}$. In this assessment $27.27 \%$ of hospital stores didn't have consistent power supply or generator. Similarly $27.27 \%$ of store didn't have thermometer in their rooms. It was similar from study done in Rwanda and Uganda where the survey found that protection from sunlight was not always ensured (70\% for main storage, $43 \%$ for other rooms) [13, 18]. This could be due to many of those storage spaces were not constructed for storage purpose of laboratory commodities and medical supplies rather constructed for other purposes. 
$36.36 \%$ of medical stores in this assessment did separation of flammable chemicals, hazardous chemicals, and damaged/expired laboratory commodities. This finding was somewhat smaller than a study conducted in Rwanda where dangerous and flammable products were adequately stored in separate spaces in $43 \%$ of the facilities and higher than a study conducted in Lesotho where none of the laboratories practiced in their study reported the separation of damaged/or expired supplies from usable products $[13,14]$. The difference could be due to lack of adequate rooms, carelessness of the staffs or absence of guidelines how to separately store these products.

With respect to availability of standard storage space, $63.64 \%$ of medical store had shelving and boxes with sufficient storage space to store all available medical laboratory supplies. This result was much lower than a study from Rwanda where most facilities (98\%) reported having shelving [13]. This lower availability of shelves and boxes in comparison with previous studies could be due to poor financial ability of our study facilities to accomplish these requirements or small sample size.

Among all store managers, less than half (45.5\%) of said that they had received training about storage of medical supplies. This was much higher than a study done in Kenya where only $2.6 \%$ of health professionals had received some training [15]. This high percent in our study could be due to involvement of only store managers excluding other health professionals and may be due to low sample size of participants in our study.

Regarding the presence of written guidelines, $45.45 \%$ had written guideline for storing laboratory supplies or commodities according to their specification. This result was higher than the study conducted in Lesotho and Malawi, where all laboratories reported that they had no written guidelines for storage of laboratory supplies according to their specifications $[14,16]$. This higher number could be due to better use of guidelines in our study since all facilities were hospitals.

In all hospital stores, store managers were pharmacist. From all store managers $81.81 \%$ know appropriate storage of frozen items and the remaining didn't know. Only $36.36 \%$ of store managers know what quality commodity mean whereas $63.64 \%$ didn't know the meaning which is similar with study in Zambia. [10]

$36.36 \%$ of store managers didn't take any actions when temperature becomes out of range. $27.27 \%$ of store managers didn't clean refrigerators regularly.

Neither of educational status, having training opportunities, presence of standard storage space, and presence of written guideline showed significant association with the general storage condition of laboratory commodities but
Assessment on Storage Conditions of Medical Laboratory Commodities and KAP of Store Managers at Government Hospitals in Addis Ababa, Ethiopia

\section{$\longrightarrow$}


Tesfaw, HM Hussien, $\mathrm{K}$

not receiving training had a significant association with that of the storage condition in Fisher's exact test of the analysis.

\section{CONCLUSIONS}

Almost all medical stores had storage problems. The main problems identified in this assessment are: lack of adequate number of shelves and boxes, lack of standard guidelines for storage or discard of commodities, lack of thermometer, no adequate training for store managers, not involving laboratory professionals in storage of laboratory commodities, lack of adequate power supply, insufficient knowledge, attitude and practice of store managers about proper storage conditions of commodities.

\section{COMPETING INTERESTS}

We, authors declare that we have no competing interests.

\section{AUTHORS' CONTRIBUTIONS}

Habtamu M. and Kelemework H. have contributed to the conception of the study question, designed the study, collected the data, analyzed the data, interpreted the data and drafted the manuscript

\section{REFERENCES}

[1] Annan J, Oteng-Abayie EF and Darko E. An Assessment of Health Commodities Management Practices in Health Care Delivery in Ghana: The Case of Selected Hospitals in Ashanti Region-Ghana Department of Information Systems and Decision Sciences KNUST School of Business, Ghana, 2009.

[2] USAID/DELIVER PROJECT. Laboratory logistic hand book; guide designing and managing laboratory logistic system. Arlington, Va.: USAID/DELIVER PROJECT, 2009.

[3] Marasi M, Anderson S, Printz N, Msipa P, Hamblin K, and Keddem C. Segmenting Laboratory Commodities for Logistics System Design. Arlington, Va.: USAID I DELIVER PROJECT, 2010.

[4] John Snow, Inc. /DELIVER .Guidelines for the Storage of Essential Medicines and Other Health Commodities. Arlington, Va.: John Snow, Inc. /DELIVER, 2003.

[5] WHO. Laboratory service and medical supplies. WHO, 2007.

[6] John Snow, Inc. /DELIVER. Guidelines for Managing the HIV/AIDS Supply Chain. Arlington, John Snow, Inc. /DELIVER, 2005. 
[7] WHO. Specifications and Quantities for Efficient Procurement of Essential Equipment and Laboratory Commodities for HIV Field Test Version. WHO, 2013.

[8] Birx D, de Souza M, Nkengasong JN. Laboratory challenges in the scaling up of $\mathrm{HIV}, \mathrm{TB}$, and malaria programs: the interaction of health and laboratory systems, clinical research, and service delivery. Am J Clin Pathol. 2009; 131:849-851.

[9] USAID/DELIVERPROJECT .The United States Global Health Initiative Ethiopia Global Health Initiative Strategy. Arlington, Va.: USAID/DELIVERPROJECT, 2011.

[10] USAID/DELIVERPROJECT .Harmonization of Laboratory Items in Zambia. Arlington, Va.: USAID /deliver project, 1997.

[11] Secchiero S, Sciacovelli L, Bonvicini P, Zaninotto M, and Plebani M. Assessment of package inserts for diagnostic kits. Clin Chem Lab Med.1999; 37(6), 663-665.

[12] John N, kengasong N and Tsehaynesh M.Critical Role of Developing National Strategic Plans as a Guide to Strengthen Laboratory Health Systems in ResourcePoor Settings, 2009.

[13] Lijdsman C, Onyango C, Gatera A, Saleeb S, Tarrafeta B, and Gabra M. Assessment of the Health Commodity Supply Sector in Rwanda. August 2003.

[14] Pharasi B. Assessment of the HIV/AIDS Medical Supplies and Laboratory Commodities Supply Chain in Lesotho, November 2007.

[15] Marc L, Julie D, Stephen M, Tiberius B, and Kate H. Kenya health system assessment, 2010.

[16] Butao, Doris, Felling B, and Msipa P. Malawi Laboratory Services and Supply Chain Assessment. Arlington, Va.: USAID/DELIVER PROJECT, Task Order 1; 2009.[accessed on 10 April 2016)

Available at pdf.usaid.gov pdf docs/Pnadp587.pdf

[17] Barry C,Erin H, Ali K, Daniel M, Nyinondi S, Rosche T et al. Tanzania:Integrated Logistics System Pilot-Test Evaluation. Arlington, Va.: DELIVER, for USAID; 2005.[accessed on 07 May2016) Available at https://www.usaid.gov

[18] Francis O, Anthony M, Augustin M, Benson T, Jacinto A, Elizabeth T, Et Al. Assessment Of Uganda Laboratory Logistics System. Arlington, Va.: JSI/ DELIVER PROJECT; 2006
Assessment on

Storage Conditions of Medical Laboratory

Commodities and KAP of

Store Managers at Government Hospitals in Addis Ababa, Ethiopia 